\title{
Adolescents' Commitment to Developing Talent: The Role of Peers in Continuing Motivation for Sports and the Arts
}

\author{
Helen Patrick, ${ }^{1}$ Allison M. Ryan, ${ }^{2}$ Corinne Alfeld-Liro, ${ }^{3}$ \\ Jennifer A. Fredricks, ${ }^{4}$ Ludmila Z. Hruda, ${ }^{5}$ and Jacquelynne S. Eccles ${ }^{6}$ \\ Received October 14, 1998; accepted August 9, 1999
}

The role of peer relationships in supporting or hindering adolescents' talent development has received little research attention, despite the importance of peers in adolescents' lives. We conducted semi-structured in-depth interviews with 41 adolescents talented in sports or the arts, and their parents, to investigate (a) the

This study was partly funded by a grant from the National Institute of Child Health and Human Development to Drs. Jacquelynne S. Eccles, Rena D. Harold, Phyllis C. Blumenfeld, and Allan Wigfield. An earlier version of this study was presented at the biennial meeting of the Society for Research in Child Development, Washington, DC, in April 1997.

'Assistant Professor, Department of Educational and Psychological Foundations, Northern Illinois University. Received Ph.D. in Education and Psychology from the University of Michigan, Ann Arbor. Research interests include children's and adolescents' motivation, and social processes and contexts that support motivation and engagement. To whom correspondence should be addressed at 225 Graham Hall, Northern Illinois University, DeKalb, IL 60115. Email: hpatrick@niu.edu.

${ }^{2}$ Assistant Professor, Educational Psychology Department, University of Illinois, Urbana-Champaign. Received Ph.D. in Education and Psychology from the University of Michigan, Ann Arbor. Main research interests are understanding how features of the classroom and peer group context relate to students' achievement beliefs and behaviors, including students' beliefs and behaviors regarding help seeking in the classroom.

${ }^{3}$ Postdoctoral Research Fellow, Max Planck Institute for Human Development, Berlin, Germany. Received Ph.D. in Education and Psychology from the University of Michigan. Ann Arbor. Main research interests are career development and the school-to-work transition in late adolescence and young adulthood, with particular emphasis on gender and social class.

${ }^{4}$ Postdoctoral Research Fellow, MacArthur Network for Successful Pathways through Middle Childhood. Received Ph.D. in Education and Psychology from the University of Michigan, Ann Arbor. Research interests are gender role socialization, motivation, and extracurricular participation.

${ }^{5}$ Graduate Student, Combined Program in Education and Psychology, University of Michigan, Ann Arbor. Research interests are achievement and social motivation, and students' self-presentation in the classroom

${ }^{6}$ Professor of Psychology, Women's Studies, and Education, and Research Scientist, Institute for Social Research, University of Michigan. Received her Ph.D. in Developmental Psychology from UCLA Research interests include gender-role socialization, social development in the family and school context, and classroom influences on student motivation. 
role of peer relationships in adolescents' continued involvement in their talent activities, $(b)$ possible differences in this role by activity domain, and (c) possible gender differences. Thematic analysis indicated that peers typically played a positive function in supporting the continued involvement of talented adolescents in their talent activities. There were differences in opportunities for peer relationships and social satisfaction between in-school and out-of school activities, but not between activity domains. Both males and females mentioned equally social benefits of such involvement. However, females mentioned receiving negative peer attention more frequently than males, and more often cited social dissatisfaction as a significant contributor to decreased involvement or quitting.

\section{INTRODUCTION}

Watching displays of talented athletes, artists, musicians, or dancers, it is apparent that those individuals have committed considerable time and energy to developing their talent. Talent development requires high levels of practice and commitment, and decisions about the level of one's commitment are often made during adolescence (Csikszentmihalyi, Rathunde, and Whalen, 1993; Fredricks et al., 1997). Only some adolescents who show indications of promise, however, choose to respond to the need for increased effort and commitment in order to develop their talent, whereas others elect to maintain involvement at lower levels or quit altogether. What factors support or hinder the commitment to talent development of adolescents who have exhibited early talent and high levels of involvement as children?

Adolescents' decisions about commitment to their talent activities appear to be related less to their actual level of competence or ability, and more to individuals' motivational characteristics (Csikszentmihalyi et al., 1993; Fredricks et al., 1997). In outlining needed directions for future research regarding the development of talent, Horowitz and O'Brien (1986) called for studies that consider motivational and socialization factors that nurture and maintain talent. Motivational characteristics that have been investigated include adolescents' reports of their undivided interest or "flow" while engaged in their talent activities (Csikszentmihalyi et al., 1993; Rathunde and Csikszentmihalyi, 1993), their experiences of enjoyment and fun (Scanlan, Carpenter, Lobel, and Simons, 1993; Scanlan, Stein, and Ravizza, 1989; Weiss and Petlichkoff, 1989), and the perceived value of the activities (Barber and Eccles, 1997; Eccles and Barber, 1999; Fredricks et al., 1997). With regard to socializing agents, talented children's and adolescents' commitment to developing their talent has been associated with features of the family and home environment (Bloom, 1985; Csikszentmihalyi et al., 1993; Monsaas and Engelhard, 1990), and with other adult figures such as coaches, teachers, and mentors (Bloom, 1985; Csikszentmihalyi et al., 1993; Scanlan et al., 1993; Weiss and Petlichkoff, 1989).

One group that is particularly important to adolescents is peers. Csikszentmihalyi and his colleagues (1993) found that adolescents who were 
talented in either academic or nonacademic activities spent less time with their friends than did nontalented adolescents. Research that has investigated sports participation has found that peers play an important role in influencing children's and adolescents' participation in sports activities (Duncan, 1993; Kunesh, Hasbrook, and Lewthwaite, 1992; Scanlan et al., 1993; Weiss, Smith, and Theeboom, 1996). However, it is unclear to what extent those findings relate specifically to talented adolescents. Furthermore, because there has been little research about peer relationships and adolescents' commitment to talent development within the arts, it is not known if peers play a similar role as in sports. In the current study, we used in-depth interviews with adolescents talented in sports or the arts, and their parents, to examine the role of peer relationships with respect to adolescents' commitment to their talent. Additionally, we added to previous research by considering possible domain differences and gender differences regarding the role of peer relationships for continued involvement.

When investigating talent, there is always an issue of subject selection, or how talented the individuals must be for inclusion in studies. There have been a few studies of exceptionally talented individuals, such as the Olympic swimmers, concert pianists, and world-famous sculptors in Bloom's (1985) study, as well as Feldman's (1986) research of child prodigies. However, of the many talented dolescents who appear to have the potential to become exceptionally successful in their talent activity, very few ever do. Further, those who become successful as adults are not always those who were considered the most talented children or adolescents (Csikszentmihalyi et al., 1993). Therefore, in addition to research focused on those exceedingly precocious and successful individuals, there is a need for researchers to investigate factors that influence the continued involvement of the far greater number of individuals who would be thought of more generally as talented. In the current study, we focused on adolescents who, during middle childhood and early adolescence, viewed themselves and were viewed by others as being among the best and most involved of their agemates in at least one activity within sports or the arts. However, we expect that very few, if any, will achieve the prominence that would have been necessary for inclusion in Bloom's (1985) or Feldman's (1986) research.

The first issue we investigated involved the role that peers play with regard to supporting or undermining talented adolescents' commitment to, and involvement in, their talent activities. There are many reasons to suggest that peer relationships may be important to adolescents' decisions about the extent to which they continue to invest their time and energies in such activities. Peer relationships take on special significance during adolescence, compared to earlier periods of development (Berndt, 1982; Hartup, 1993; Savin-Williams and Berndt, 1990). During adolescence, the peer group becomes more salient and important to adolescents, and their social roles and relationships both within the family and within peer networks typically become redefined (Savin-Williams and Berndt, 1990). 
With adolescence comes an increase in the time spent with peers, which may influence the time that adolescents have for pursuing their talent. Adolescents in Western countries report that they spend more time with their peers than with family members or on their own, which represents a significant developmental change compared to pre-adolescence (Csikszentmihalyi and Larson, 1984; Savin-Williams and Berndt, 1990). If talented adolescents spend a greater proportion of their time with peers, their time available for pursuing talent activities may be constrained. Conversely, those adolescents who choose to increase their commitment to their talent activities may find they have less opportunity for investing in social relationships. Csikszentmihalyi and his colleagues (1993) found that talented adolescents spent significantly less time socializing with peers, including talking to and going out with friends and attending parties, than their less talented peers. The increased time commitment needed for talent development, coupled with the increased desire for peer relationships that is typical during adolescence, has led Csikszentmihalyi (Csikszentmihalyi et al., 1993; Whalen and Csikszentmihalyi, 1989) to argue that adolescence is a time of potential conflict between the necessary conditions for talent development versus maintaining satisfying peer relationships, and to speculate that talented adolescents' concerns about their peer group may interfere with the dedication necessary for continued talent development.

In addition to influencing time use, peers may affect talented adolescents' decisions about their involvement in talent activities through the kind and amount of social support they provide. Adolescents report that they turn increasingly to their peers for social support as they move into, and through, adolescence (Berndt, 1982; Buhrmester and Furman, 1987; Furman and Buhrmester, 1992). It seems reasonable that perceived peer support for continuing with their talent activities would be a factor contributing to adolescents' commitment to that talent.

Another reason why adolescents' relationships with peers may be associated with their commitment to their talent is related to the link between identity perceptions and peer relationships. Adolescents' developing perceptions of themselveswho they are and what they are good and not good at, are expected to contribute to their activity involvement and commitment. Peers can influence adolescents' perceptions of identity through the messages they explicitly and implicitly convey. Intimate disclosures between peers are a feature of adolescent friendships (Berndt, 1982; Buhrmester and Furman, 1987). Adolescents report that they can most "be themselves" when they are with their peers (Savin-Williams and Berndt, 1990). The pooled appraisals of important others, including agemates, become incorporated into adolescents' self-image-a process that has been called the looking glass self (Cooley, 1902, in Harter, 1990). Through such disclosures and honest feedback, adolescents can encourage or discourage others' commitment to talent activities because peer evaluation can affect one's sense of self-worth and selfesteem (O’Brien and Bierman, 1988). 
Another way that peers can contribute to adolescents' identity development is through the provision of opportunities for social comparison; peers can function to accentuate adolescents' individuality and assist them in differentiating their own identity from those of others around them (Harter, 1990; Savin-Williams and Berndt, 1990). Such social comparison may also contribute to adolescents' commitment to talent activities.

Further indications about the importance of investigating associations between talented adolescents' peer relationships and continued motivation for their talent activity can be found in research in academic activities. Within educational psychology, there has been increasing recognition of the importance of peers with respect to children's and adolescents' motivation for academics (see Juvonen and Wentzel, 1996). Other researchers (e.g., Baumeister and Leary, 1995) who have investigated individuals' more general, fundamental motivating forces have concluded that a strong and probably under-acknowledged motivating force within humans is their desire for close, interpersonal attachments and feelings of belonging socially. For adolescents, the peer group would most likely be a significant target of such social goals or desires.

In summary, peer relationships are expected to be associated with adolescents' commitment to developing their talent, because they have been found to be related to adolescents' use of time, perceived social support, and identity development. Further, forming and maintaining satisfying social relationships is a significant motivational goal that is likely to be particularly important to adolescents. Extant literature has identified both possible positive and negative paths of peer influence. With respect to talent development, peers may encourage and support commitment through such means as enhancing adolescents' enjoyment of the activity and bolstering their talent-related self-concept, but peers may also detract from commitment by distracting their focus.

The second issue we addressed was whether the role of adolescents' peer relationships differed with respect to the type of domain in which they were involved. There has been only a little comparison of talented individuals across different activities (e.g., Bloom, 1985). However, Whalen and Csikszentmihalyi (1989) suggested that relations between adolescents' talent and their self-image may vary across different domains. At present, comparisons across domains are difficult, because so little research has addressed the role of peers outside of sports and academics. Although the study by Csikszentmihalyi and his colleagues (1993) included adolescents who were talented in nonacademic activities (vocal or instrumental music, athletics, art), they did not report many of the findings separately by domain (e.g., athletics compared to music), nor did they distinguish them from those gathered from adolescents who were talented in academic (mathematics, science) activities. Therefore, it is not clear whether there are differences between adolescents in academic versus nonacademic activities, or differences among various nonacademic activities. Because there has been very little research addressing 
the association between adolescents' peer relationships and involvement in the arts, this investigation was considered exploratory and no hypotheses about domain differences were made.

The third issue we considered was gender. Although there has been little research directly investigating friendships and activity participation separately for males and females, there is considerable evidence that adolescents' friendships and perceptions of their peer relationships differ by gender. In particular, female adolescents' peer relationships are characterized by greater intimacy (Berndt, 1982; Clark-Lempers, Lempers, and Ho, 1991), and by smaller and more exclusive peer groups, than males' (Berndt, 1982). Further, female adolescents on average value social relationships to a greater extent than do males (Eccles, 1985; Eccles and Harold, 1992). If peers do influence adolescents' commitment to their talent, then gender-based differences in the nature of peer relationships, and their perceived value, may contribute to differential relations between talent development and peers for males and females.

\section{PURPOSE}

In summary, we investigated: (a) the role of peer relationships with respect to adolescents' continued involvement in one or more fields of talent (sports, music, drama, dance, art), (b) possible differences in this role by activity domain, and (c) possible gender differences. The adolescents were not child prodigies, but comprised a group from a large longitudinal study who were perceived (by themselves and by others) as being the most competent, involved, and interested in sports or the arts.

We used a qualitative approach to examine adolescents' and parents' reports of associations between peer relationships and their continued involvement in talent activities. Specifically, using semi-structured, in-depth interviews allowed us to explore how the participants themselves viewed relations between social relationships and activity involvement, rather than have responses constrained to previously derived categories.

\section{METHOD}

\section{Participants}

Participants were 41 adolescents ( 15 male, 26 female) in grades 9,10 , and 12 (approximately equal numbers from each grade), and their parents. All adolescents were talented in at least one nonacademic domain, such as sports, instrumental music, singing, drama, dance, and art. Of the participants, 24 were involved in a 
single domain, whereas 17 pursued more than one talent domain (e.g., choir and sports). Twenty-seven of the adolescents pursued sports activities (e.g., football, soccer, basketball, gymnastics); 12 were talented in instrumental music (e.g., piano, violin, guitar, trumpet); 9 sang in a choir; 6 were involved in dance; 5 were in drama; and 2 were involved in art. The adolescents were all European American and came from middle-class socioeconomic backgrounds in southeastern Michigan.

The adolescents in the current study were selected from 873 participants in an ongoing larger longitudinal study about activity choice in childhood and adolescence (Eccles, Blumenfeld, Harold, and Wigfield, 1990). The participants of this larger sample were also almost all European American and from middle-class backgrounds. We used a number of indicators to identify the talented adolescents, including parent, teacher, and self-ratings of the adolescents' competence, perceived value, and time spent per week engaged in their talent activity. First, we used survey data collected in 1989 and 1990 (when the participants were in elementary school) on all 873 participants to create separate composite measures of perceived competence, value, and time involvement in a nonacademic domain. These three composites were then used to identify adolescents who were perceived (by themselves and by parents and teachers) as being highly competent ( 7 on a 7-point scale) in at least one nonacademic domain, who valued that domain very highly (7 on a 7 -point scale), and who spent considerable time (from self- or parental report) involved in that activity (more than 5 hours per week in music or more than 7 hours per week in sports). Of these participants, we then identified those who had maintained their high levels of competence, value, and involvement in adolescence by examining information obtained both through telephone interviews with parents and survey data collected from the students in 1994-1995. We also identified those who had recently quit their activity but who met our definition for talent and high involvement in middle childhood, in order to interview them about this decision.

Through the initial identification procedure we identified 65 adolescents as being talented. However, 6 were excluded from the sample because they had moved out of the geographic region. Of the remaining 59 adolescents and their families, 50 agreed to participate. An additional 8 families (of the consenting 50) were not interviewed because a mutually agreeable time for conducting the interviews could not be found within the research time frame. Further, one set of interviews was excluded from analysis because of technical difficulties with the audiotapes, leaving a final sample of 41 adolescents and 41 parents.

\section{Interview Protocol}

We conducted semi-structured, in-depth interviews to prompt discussion about each adolescent's involvement in his or her activity from childhood to 
adolescence. The interviewers followed a protocol of questions but let the participants answer the questions in an open-ended manner. ${ }^{7}$ The interviews for the adolescents and their parents were comparable, with the exception of asking the adolescents more detailed questions regarding their feelings about their involvement in their activity. The questions were organized around a number of areas, including: (a) the adolescent's history of involvement and accomplishment in the talent activity; (b) the adolescent's hopes and plans for the future, both in general and for the talent activity; (c) impact of the talent activity on other areas of life, such as school, peer relationships, and family relationships; and, (d) the impact and importance of significant others, such as family members, coaches/teachers, and peers, on involvement in the talent activity. The following is an extract about social relationships from the adolescent interview:

Can you tell me which people in your life are most important for your participation in [activity]. Who are they?

Now, what about people who have caused you stress or made things difficult for you to participate in [activity]. Who are they?

Now think about your relationships with these people and your involvement in [activity] Do they influence or affect your involvement in [activity], and does your involvement affect them?

In responding to comments, interviewers used both clarification probes ("What do you mean by...?") and elaboration probes ("Can you give me an example of ...?") throughout the interviews to increase the clarity and richness of the responses. Therefore, interviewers encouraged adolescents to describe their experiences and perceptions regarding involvement, but did not ask any leading questions, such as asking directly whether or not participation helped them make friends. In instances where adolescents were involved in more than one activity or domain, the same questions were asked about each activity separately. The participants were invited to make additional comments or ask questions at the end of the interview.

\section{Procedure}

Before beginning, interviewers attended two day-long sessions on conducting semi-structured interviews given by researchers experienced in this method. These sessions covered such topics as establishing rapport, effective communication techniques, specific strategies for eliciting responses, and ethical issues. Interviewers then conducted and tape-recorded practice interviews for subsequent feedback from the workshop leaders.

Each adolescent's family was contacted by phone and informed that the adolescent had been identified from previously completed surveys as being one of the

${ }^{7} \mathrm{~A}$ copy of the interview protocol is available on request from the first author. 
most highly involved in their activity. The parent was asked whether both they and their adolescent would agree to a paid interview about the adolescent's involvement in the talent activity. Arrangements were made for the interviewer to visit the family's home at a time convenient to both the adolescent and parent.

Individual semi-structured interviews were conducted with the adolescent and with one parent (typically the mother) in their home by one of five female interviewers during the fall and winter of 1995-1996. Participants were assured that their responses would be kept confidential, that they did not need to answer any questions they would rather not, and that all identifying characteristics would be altered before the findings were reported. ${ }^{8}$ Participants were also given an opportunity to ask questions. Written consent was obtained from all participants before the interviews commenced, and participants were paid $^{9}$ on completion of their interview. Each interview lasted from one to one-and-a-balf hours, was audiotaped, and was subsequently transcribed and analyzed.

\section{Analysis Overview}

Data analysis involved induction, deduction, and verification techniques (Miles and Huberman, 1994). At all stages of the analysis, we met weekly or biweekly to discuss emerging themes and reach consensus before proceeding to the next phase. After completing the interviews, each interviewer first listened to the audiotapes of the interviews she conducted and wrote a structured summary of the main issues for each case. We discussed those summaries over a number of weeks, and generated a list of dominant themes. Next, we developed a list of codes from these common themes (e.g., social benefits, social costs, social support, competition, enjoyment). Each interview was then transcribed and we coded them using HyperResearch (Hesse-Biber, Kinder, Dupis, Dupis, and Tornabene, 1994) - a computer program for coding qualitative data - with the previously generated codes. We coded each transcript in alternating teams of two so that we could discuss immediately which code to use and why. When a disagreement arose, the entire team met to discuss the meaning of the theme and to reach an agreement on which code to use.

In the next phase of analysis we examined printed reports of codes from HyperResearch. Our criteria for considering a theme to be associated with an individual was if the associated code was used at least once for a case. Given the interview questions were of a general and open-ended nature, we considered the mentioning of an issue even once to be significant evidence. We looked for

\footnotetext{
${ }^{8}$ All identifying features, including names of participants, their schools, and their districts have been altered to protect the participants' confidentiality.

${ }^{9}$ The adolescent was paid $\$ 10$ and the parent was paid $\$ 15$ for the interview. The difference in payment was because we had also recently collected surveys and had paid the adolescent $\$ 10$ and the parent $\$ 5$ for completing the survey. Therefore, the total paid to each participant was $\$ 20$ for both survey and interview.
} 
commonalties and differences among the adolescents for each code, taking into account whether or not they were still involved in the activity, their plans for the immediate future, the activity type, and their gender. The reports were then exchanged with another team member to verify conclusions. Finally, the group came back together to share ideas and reach consensus about emerging themes and how they fit together.

\section{RESULTS}

Thematic analysis of the interviews indicated that peer relationships were particularly salient, and played an important role in adolescents' continuing involvement in, and commitment to, their talent. This was considered noteworthy because, as indicated, the participants were asked only general, nonleading questions to allow them to express what was most important to their involvement in the activities, and specific associations were not suggested. Two general themes were mentioned frequently by both the adolescents and their parents: (a) perceptions of social benefits and negative attention accrued through involvement in a talent area, and (b) satisfaction in peer relationships as supporting or undermining adolescents' commitment to their talent. We present these themes in the following sections, with totals (and percentages) of the number of adolescents who made each comment and examples taken from the interviews. Within each theme we also present results of our investigations into potential differences by activity type and gender.

\section{Perceived Social Benefits and Negative Attention Accrued Through Involvement}

One of the most consistent themes involved the social benefits adolescents perceived as accruing from their involvement in the talent activities. Over half the adolescents $(23,56 \%)$ told us their involvement provided a significant opportunity to make friends. In particular, they reported that their involvement increased the extent to which they came into contact with different peers and led to an increase in the number of friends that they had. This appeared to be viewed as a considerable benefit, and one that was valued widely across all of the domains. For example, adolescents told us:

I played three sports so it was easy to make new friends. (Female, 10th grade, soccer)

[Drama] let me be with more people and do more group activities, parties, you know, friends. (Male, 10th grade, drama)

People who aren't on [a team]-I don't think they have as many friends, as people who do get involved. (Female, 9 th grade, swimming) 
Further, over one-third of the adolescents $(15,37 \%)$ told us that activity involvement enhanced their social skills and confidence in relating to peers. For example, adolescents said:

It just enhanced my people skills and gave me a better sense of belonging. (Male, 12th grade, drama)

Through dance, just stuff that I've done just makes me not shy any more. It's like I'm not afraid of people. (Female, 10th grade, dance)

Involvement in some activities also provided opportunities for adolescents to have contact with, and perhaps become friends with, students from different grades than themselves. This was seen as particularly advantageous for younger students, who would not otherwise have come into contact with older, higher status students in the typically grade-segregated high school environment. With regard to high school sports, extremely talented adolescents could be selected for the varsity team as freshmen or sophomores and thus play alongside older teammates. In school band, orchestra, choir, and drama groups, however, adolescents at all levels of competence were grouped together across grade levels. Eight (20\%) participants spoke of these cross-grade groupings as being beneficial:

Choir's helped me a lot. The fact that when I was a freshman I knew three other classes worth of people. So I knew seniors and juniors and sophomores. (Male, 12th grade, choir)

And a couple of these kids on this team are sophomores. They're older, and I think it's helped her kind of a little to get to know more older kids and just to have more connections with school, which will give her confidence. (Mother of female, 9th grade, soccer)

However, one talented soccer player and her mother independently indicated that talent involvement with considerably older peers may not always be desirable. The adolescent had been the only junior high school student on a soccer team of high school girls. Her mother said:

Kathryn was on a team of kids who were much older. I don't think she felt like she really fit in-well, because the kids were older. It wasn't that she wasn't making any friends, but there was no real connection. (Mother of female, 9 th grade, soccer)

The adolescent noted she became much happier when she transferred to an equally competitive team of young women her own age. Her mother concurred, saying that now "athletics is the social part of her life." The difference between this case, and the others who saw across-grade grouping as beneficial, may be that she was the only person among a group of older adolescents, rather than there being others similar in age to herself.

In addition to gaining a more extensive social network, more than half of the adolescents $(23,57 \%)$ commented on the intensive nature of friendships that were formed with others within the activities. They described their relationships as having a special sense of intimacy and fellowship - a stronger bond than other friendships. 
Hamilton Players Group at my school is like a family. Everybody is there for everybody. It's like a real close group. (Male, 12th grade, drama)

The best experiences were being with the kids every single day, and that's why I miss it [i.e., the summer symphony program] so much. You're with these kids for three months every single day, practically, except for two weeks.... It was a bonding experience. (Female, 12th grade, violin)

She has made some closer connections to these kids [on soccer team]. I think that's kind of a more of a family feeling for her.... Because they're very intimate and really involved. You know, they play together week after week after week, and they shove up against each other. (Mother of female, 9 th grade, soccer)

However, those positive social benefits were not experienced by all of the talented adolescents. Three females in the arts discussed how they were viewed as strange and different by their school peers, largely because of their passion and talent for their activity. These three were among the most competent and invested adolescents of all those interviewed. One of them, a 12 th grade violinist, told us that her achievements in music were not generally respected by her peers at school, many of whom called her an "orch dork." Reciprocally, she expressed little regard for her peers in the school orchestra:

The kids in the school orchestra-they don't care about it. They do it because they think it's going to be an easy grade and they don't really care. They don't practice. They don't know anything. (Female, 12th grade, violin)

She did, however, find a satisfying peer group in the youth symphony she played in:

I have some really good friends in the youth symphony that play. When I toured Europe I made a lot of good friends and they all played the violin and different instruments. I get along well with people who love music ... It's a good bond between people. You're both, like, on the same level, you have something in common right away. So I found that I relate better with people who have set standards in music for themselves.

It may be important for adolescents to find a social group of peers whose values and attitudes regarding the activity are consistent with their own; particularly talented and passionate adolescents may draw their social network from more select places than school orchestras or sports teams. The importance of finding a peer group that is supportive of adolescents' continued involvement is also illustrated with the two other highly talented and committed adolescents who had trouble locating such a peer group. The mother of an adolescent who was involved in drama and theater told us:

She did have a very bad time as a young teenager. Some of it was, I think, that she was just so very different from other girls her age. She was 13 or 14 , and she was doing professional theater downtown at the Ed theater... and then you go to a very middle class, suburban white junior high, where things are catty. And she's just a creative different kid. I think it was because she was so creative, so different that she didn't always fit in very well-she was so different and she-I think she got very badly hurt in school and was very badly shunned for several years by her peers. (Mother of female, 12th grade, drama) 
The situation improved for this adolescent actress when she reached high school and joined the drama club. Her mother said:

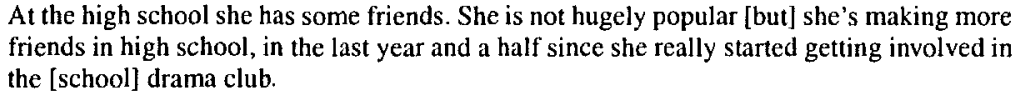

At the high school she has some friends. She is not hugely popular [but] she's making more friends in high school, in the last year and a half since she really started getting involved in the [school] drama club.

Another adolescent, talented in singing, said:

\begin{abstract}
Kids are cruel to certain people that they single out as being different or strange. Like me. My interest in music was a very strange thing at my school... People usually teased me about things, you know, about how I had an operatic voice. (Female, 10th grade, singing)
\end{abstract}

She had anticipated that involvement in the Creative and Performing Arts (CAPA) program at her high school would provide a peer group who shared her interests, but she was disappointed; her situation did not improve. Her mother explained:

I think she thought she would burst in and be popular now. We really expected things to be better for her in high school... I think she was hoping that when she got into CAPA, I think she was expecting [there would be] more kids like her and there wasn't. She expected more [kids] to be what they'd think of as weird, because she is different.

\title{
Activity Type
}

The positive social aspects of talent involvement were mentioned equally by adolescents in all types of activities. However, the three adolescents who perceived receiving negative attention from peers were in the arts-one from each of instrumental music, drama, and choir; none of the adolescents in sports reported such costs.

\section{Gender}

In general, both males and females were equally likely to mention perceiving social benefits for participating in their talent activities, as indicated by nonsignificant Chi-square statistics. More than half the females $(15,58 \%)$ and males $(8,53 \%)$ mentioned having increased opportunities for making friends. Males and females mentioned equally frequently both perceiving advantages such as increased confidence and social skills (males, $40 \%$; females, $35 \%$ ), and benefits from participating with students of different ages (males, $20 \%$; females, $19 \%$ ). Interestingly, perceptions of having close and special friendships with peers within their talent was also noted to a similar extent by females $(15,58 \%)$ and males $(8,53 \%)$. In contrast to comments about social benefits, only females reported perceiving negative peer attention for their talent involvement. Three females (12\%) reported that their passion for, and involvement in, their talent earned them negative responses from their peers; no males reported such perceptions. However this apparent gender difference was not statistically significant $\left(\chi^{2}=1.03\right)$. 


\section{Summary}

In summary, more than half of the talented adolescents spontaneously expressed the belief that their involvement in their talent activities afforded them important opportunities for making friends, and over one-third commented on opportunities for enhancing their social skills in general. Some activities or teams, particularly band, orchestra, choir, and drama club, enabled adolescents from different grades to interact closely, and this was often commented on favorably by them and their parents. More than half of the adolescents noted a special sense of closeness among the peers who also participated in those activities. There was a striking similarity in responses across both activity domain and gender.

\section{Satisfaction with Peer Relationships Supporting or Undermining Commitment}

In addition to the social benefits discussed above, the adolescents also typically indicated that the social dimensions of their involvement were important to their continued commitment to their talent. Conversely, when pursuit of their talent was perceived as having substantial social costs, it appeared that adolescents often then reduced involvement in that activity.

Over one-third $(15,37 \%)$ of adolescents told us that the social aspects of peer relationships, such as being with their friends, associated with activity involvement enhanced considerably their enjoyment of engaging in that activity. Often times, when the adolescents were asked why they liked engaging in the activities, their answers were similar to one 9th grader's, who said simply "Because I'm with my friends" (Female, 9th grade, soccer). Other adolescents told us:

\footnotetext{
Marching band-that made school so much fun, because we're always doing something together. People in the band-they were all very friendly, and so they make it a lot more fun. They're always friendly and they'll always include you. And then just going out there in competition, it's a lot of fun. Waiting for your [team's] score and stuff. (Female, 9th grade, flute)

During the summer, we have tournaments that last weekends, and weeks, and so we get to spend time with our friends and our players, and have dinner parties and things like that. (Female, 9th grade, soccer)
}

In contrast to the majority of adolescents who said that involvement in their activity increased the time they could spend with their friends, around one-fourth $(11,27 \%)$ reported that pursuing their talent took time away from being with friends. In all but one of these cases, the adolescents were not involved in schoolsponsored activities, but participated in activities in organizational settings outside of school. Some of those adolescents told us: 
[Music] doesn't really get in the way, except on weekends. You know, you're just like, "Man, I want to go out with my friends today." (Male, 10th grade, cello)

I'd like to do more with my other friends, but I don't have the time ... I don't like not being able to do things with school friends all the time. They're always asking me to come over, and I'll be like, "No, I can't. I have gymnastics. I'm sorry." So, I don't get to go out very often. I don't like that. (Female, 10th grade, gymnastics)

By far the majority of the interviews revealed that adolescents' relationships with their peers enhanced their continued investment in a talent activity. However, friendships interfered with the talent development of three (7\%) adolescents. One mother described a situation in which her adolescent's concern for his friends' feelings held him back from reaching his potential in the school orchestra.

The orchestra leader encouraged Mark to challenge people. When you challenge people you take over their chair. It's kind of a demotion for that person, but you get raised up. Well, Mark is to the point where he's known these people for so long that he doesn't want to challenge them. ... I think he could go a lot farther in his music if he'd be more assertive and say, "I want first chair," and challenge these people ... he just doesn't want to hurt these people's feelings. And when you question him about it, why he doesn't do it, it's like, "He's my friend." (Mother of male, 10th grade, cello)

Likewise, a 9 th grade gymnast indicated that her close friendships with the other girls at the gym were a mixed blessing. Apparently her supportive relationships with one friend in particular both helped to keep her involved in her sport, especially at times of frustration, and impeded her talent development. She reported that she and her friend often made up each other's floor routines, picked out each other's music, and noted, "We've discouraged each other from quitting a lot." However, this bond created a sense of loyalty and social commitment that held her back from advancing to a higher caliber gym or coach. For example, she also remarked:

A lot of times you want to go to a different gym, to better coaches, and [my friend would say] "No, don't, -stay." (Female, 9th grade, gymnastics)

Conversely, five (12\%) adolescents reported that striving to do well in their talent activities threatened to affect previous positive relationships with friends. One adolescent described the awkwardness of competing with her friends; after one soccer game her best friend reportedly said, "Geez, you're good. I'm so scared that you're going to take my place" (Female, 9th grade, soccer). Similarly, a mother told us about her daughter's early acting endeavors at high school:

She was there and knew all her lines and all her blocking and all her songs and all her dances. One of the senior girls said, "You know what? You're making me look really bad here." (Mother of female, 12th grade, drama)

One adolescent reported that she could not resolve the bad feelings that accompanied the competition with a friend over a place on a soccer team:

I'm not very good friends with her any more because, I think because, I tried out for my team again and I made it and she didn't. So I' $m$ kind of disappointed in her, and I felt bad, so 1 just let her go. (Female, 9th grade, soccer) 
Whereas it appeared that being able to spend time with friends contributed to generally positive perceptions of their engagement in talent activities, it also appeared that adolescents' perceptions of dissatisfaction with their social life led to an undermining of enjoyment and motivation. Seven (17\%) adolescents reported they had recently lessened their time or psychological commitment to their activity. Of those, three transferred their energies to another activity with potentially greater social benefits. For example, one adolescent who had been dancing in a communitybased studio for nine years appeared to be redirecting her energies into a related but different activity, cheerleading, largely because it provided her with more opportunities to have fun with her friends at school and to extend her social network. Whereas she viewed dance as interfering with her social life, she saw cheerleading as a more social endeavor with both more team camaraderie and greater social opportunities:

[Cheerleading's better] because, like, it's involved in the school, and you make, like, so many new friends, and it's fun being at all the games and everything. You become friends with, like the football players and the basketball players. (Female, 9th grade, dance, cheerleading)

Her mother noted also that her daughter was recently taking fewer dance classes and showing decreased enthusiasm for dance while becoming increasingly committed to cheerleading. The mother said:

I think because [cheerleading's] at her school, it's involving friends at her school. (Mother of female, 9 th grade, dance, cheerleading)

A second dancer was also seriously considering quitting ballet, after having taken lessons for the past 11 years. Social costs associated with her continued involvement in ballet appeared also to be a major factor in this decision. She said:

I just like to go out and do things. And every Friday and Saturday, if I were a dancer, I'd be performing. And I'd rather go out. (Female, 10th grade, ballet)

Her mother concurred, noting:

I think she loves ballet, but her social life is getting-interfering with it. (Mother of female, 10th grade, ballet)

Another adolescent who had been involved in ballet for 10 years reported that she had enjoyed ballet while she and her best friend were dancing at the same studio. However, when her friend changed studio for a better dance instructor, the adolescent's enjoyment of dance dwindled, and she quit not long afterwards. She said:

[My friend] switched into another class, and this was when I was starting to not like it. (Female, 10th grade, ballet)

Her mother concurred, commenting:

Her best friend was in it all those years, Amanda. And then, that wasn't good enough for Amanda's mother, so she put her out in West Lake with that Russian dance instructor. And 
it seemed to go, after Amanda left. ... And then Amanda was gone, and it was not cool [to dance]. (Mother of female, 10th grade, ballet)

It was not only females who quit pursuing their talent activity for social reasons. A talented male piano player who had taken lessons for 8 years, shown promise in childhood, received recognition from recitals, and been offered a job playing the piano at a local mall recently quit his piano lessons. The major reason, according to both him and his mother, was that he was unhappy that his piano lessons and practice took time away from being with his friends who spent their free time skateboarding; he wanted to be out skateboarding with them and did not want to miss any social time because of his music.

When adolescents who were involved in many activities found they had to focus their attention on one, and drop others, the social dimension was especially salient. One adolescent said:

[In high school] I had to choose between playing tennis and basketball, and I chose basketball, because that's where all my friends came from. (Female, 12th grade, basketball)

One strategy that 10 adolescents adopted to satisfy their desires both for peer relationships and social involvement and for talent development was to participate in both a more socially oriented and less prestigious team or club or group, and a more "serious" group that would develop their skills and provide challenge. For example, one 10th grade gymnast tried to balance the development of her skills and a satisfying social life by both continuing with lessons at the competitive gymnastics club where she had been taking lessons for 10 years and competing on the school gymnastics team. Her mother described how each team met different goals:

The high school gymnastics doesn't teach her the quality of tricks that she needs to compete, so she goes to the club to get that, and she goes to the high school to get fun... the kids are all having a good time. Club gymnastics is more pressure that you perform and do well. (Mother of female, 10 th grade, gymnastics)

\section{Activity Type}

Adolescents who noted that their peer relationships helped support their talent commitment were represented approximately equally in all activities. However, the 11 adolescents who commented that their involvement took time away from their peer relationships were more likely to be participating in nonschool or individual (rather than team) activities. Of those, 4 were in dance, and 1 was in each of gymnastics, piano, and art; the remaining 4 were in team or group activities ( 2 soccer, 1 drama, 1 instrumental music). Six adolescents ( 5 dance, 1 piano) quit or considered quitting their activity, largely for social reasons. 


\section{Gender}

Satisfaction with peer relationships appeared to be associated with females' commitment to maintaining talent involvement to a considerably greater extent than males', although Chi-square tests indicated that these differences were not statistically significant. Almost half $(11,42 \%)$ of the females reported that peer relationships increased their enjoyment of the activity, compared to about onefourth $(4,27 \%)$ of males. Conversely, perceptions that talent involvement took time away from friendships were mentioned by considerably more females $(9,35 \%)$ than males $(2,13 \%)$. Similarly, $5(19 \%)$ females and $1(7 \%)$ male noted that a friendship was threatened or disrupted by their own success in the talent activity. Changing one's activity or quitting altogether, primarily for social reasons, was mentioned by females (change: $3,12 \%$; quit: $3,12 \%$ ) more often than by males (change: 0 ; quit: $1,7 \%$ ).

There appeared to be little evidence of perceived gender role pressure, or adolescents feeling uncomfortable about participating in their talent activity because it was inconsistent with gender norms. In one of the most extreme cases, a mother commented that her son's participation in the school band led to some teasing from others, but it was mentioned in the context of his enjoyment of, and commitment to, band and was apparently not a source of stress for him. She said:

He'll sit around the dinner table and talk about how all of the kids make fun of the band kids. He'll say "Did you know we are band fags?" And he doesn't care. He just has a lot of fun. He really has a lot of fun with them. But, you know, it's a group, a whole bunch of kids. They all have the same interests. I think that is what he really enjoys. He found his little niche there. (Mother of male, 9th grade, trumpet, guitar, piano)

A female soccer player said:

All the giris are totally, "Oh, I've got to go shopping. You play soccer? I'd get dirty." They're like, "Oh, how can you be such a jock?" (Female, 10th grade, soccer).

However these adolescents felt sufficient support from peers within their activity that it did not appear to affect their enjoyment of, or involvement in, their activity.

\section{Summary}

It appeared that when adolescents had satisfying peer relationships within their talent activities, those relationships bolstered their enjoyment of, and commitment to, those activities. However, when adolescents felt that developing their talent was in conflict with engaging in peer relationships, their commitment to, and motivation for, their talent development was typically undermined. 


\section{DISCUSSION}

The current study adds to the literature on talented adolescents' commitment to their talent activities in several ways. It considered an important aspect of adolescents' lives-relationships with their peers-that has been underexplored with respect to talented adolescents' motivation for, and commitment to, their talent activities. Additionally, because the sample included adolescents talented in a wide range of nonacademic activities, it extends a literature that has focused primarily on adolescents' participation in sports activities. Further, it extends the research on talent to a larger, and more typical, group of talented adolescents than the child prodigies and exceptional achievers usually investigated.

Our first objective was to investigate the role of adolescents' peer relationships on their motivation and commitment to developing their talent in sports and/or the arts. The results indicated that peer relationships serve multiple roles with regard to talented adolescents' continued involvement in those nonacademic activities. The greatest proportion of the adolescents interviewed spontaneously mentioned that involvement afforded significant social benefits, particularly by providing an opportunity to make new friends and maintain a social support system. This finding is consistent with Karweit's (1983) suggestion that adolescents' socialization and development of interpersonal skills is facilitated by participation in extracurricular activities. She also noted that involvement in extracurricular activities serves to guide adolescents' choice of friends, by providing additional information about other participants' interests, skills, and personalities.

The most striking finding of the current study was the evidence that talented adolescents' relationships with their peers appeared to serve an important motivational function with respect to their continued commitment to their talent activity. Although the adolescents may not have chosen initially to engage in the activity for social reasons, the enjoyment reaped from the social aspects of that engagement did appear to enhance the enjoyment of participating and to support their continued involvement those activities. Further, it appeared that adolescents' motivation for social engagement and their desire to spend time with their peers was a significant factor influencing their talent development. The role of peers in supporting the continued interest and involvement in talent activities is consistent with research that identified the importance of perceived social support with regard to participation in sports (Scanlan et al., 1993) and exercise programs (Duncan, 1993; Duncan, Duncan, and McAuley, 1993).

Ironically, though, peer relationships may also hamper adolescents' development of their talent. In particular, when adolescents' involvement in talent activities do not afford them satisfactory opportunities for peer socialization, they may come to feel that their social goals can be met better by decreasing activity involvement. A small number of talented adolescents reported that they had recently quit, or were considering quitting, their talent activities primarily for these social reasons. This 
finding is consistent with concerns voiced by Csikszentmihalyi and his colleagues (Csikszentmihalyi et al., 1993; Whalen and Csikszentmihalyi, 1989) that talented adolescents' continued development and socialization into their talent field may lose intensity or become derailed by issues related to the peer group.

Not all of the adolescents who felt conflict between continuing with their talent and feeling satisfied with their social life quit their talent involvement, however. Some found ways to balance their competing social and talent goals, such as changing their primary activity to one that afforded more time to be with friends (e.g., from dance to cheerleading, swimming to soccer), or participating in a prestigious community-based team or group to hone skills while maintaining involvement in a less elite school team to keep up social contacts with school friends.

Importantly, peers typically played a positive function in supporting the continued involvement of talented adolescents in their activities. This finding is interesting given the scant attention that peer relationships have received in the talent literature to date. It is also important because peers are often studied with respect to adolescents' involvement in deviant or undesirable activities, such as delinquency and substance abuse; peers have rarely been studied in relation to engagement in positive, productive activities such as sports teams or orchestra (Carnegie Council on Adolescent Development, 1992).

The second issue we investigated was whether the adolescents raised different issues or reported different experiences depending on the type of activity (e.g., sports or drama or music) in which they were involved. Rather than differences between general domains, such as between sports and drama, there were indications of differences between the social opportunities afforded by school-sponsored relative to nonschool-sponsored activities. One apparent distinction was between those activities supported by and offered in schools, such as orchestra, band, choir, drama club, and school sports teams, and those that were not offered at school, such as dance and piano. It appeared that adolescents who were involved in activities not offered at their school were more likely to feel that they had to make choices between continuing their talent involvement and having a satisfying social life than were those who could pursue their talent in a school-sponsored activity. This difference is consistent with Weiss and Petlichkoff's (1989) argument that researchers who investigate motivation for continued participation in sport activities need to distinguish between school and nonschool contexts.

One implication of the apparent importance of school-sponsored nonacademic activities to adolescents' development of their talent is that schools should continue to make available, and actively support, a wide range of activities, clubs, groups, and teams. It appears that this would assist talented adolescents in balancing their social concerns with the demands for devoting increased time and energy to their activities. In addition, in assisting the balancing, schools can be supporting adolescents' opportunities to continue pursuing their talent development and lessening barriers to the fulfillment of their potential. 
The third issue we considered was gender differences in the role of talented adolescents' peer relationships with respect to their continued involvement in talent activities. There were no differences in males' and females' comments about social benefits of talent involvement. Those results were consistent with findings by Weiss and her colleagues (1996), who found very few differences between boys' and girls' comments about their best friends in sports. Interestingly, despite some evidence that female adolescents' friendships involve more intimacy than males' (e.g., Clark-Lempers et al., 1991), there were no gender differences in the adolescents' reports of having intimate friendships and of the importance of their close and supportive friendships in the current study. Buhrmester and Furman (1987) have suggested, however, that intimacy between friends may take a different form for males and females, rather than being present to a lesser degree in males' friendships. Specifically, male adolescents may be more likely to show intimacy "through actions and deeds, rather than through interpersonal disclosure of personal thoughts and feelings" (pp. 111-112).

There was a trend toward gender differences, however, in associations between adolescents' social dissatisfaction related to talent involvement and plans to quit or decrease involvement. These perceptions and decisions were mentioned more frequently by females than males. Although this difference was not statistically significant, the low power associated with the small sample size must be kept in mind. The tendency for females to be less likely than males to continue with their talent activities if involvement was perceived as jeopardizing peer relationships is consistent with research that adolescent females typically score higher on measures of social value (Eccles, 1985; Eccles and Harold, 1992), express stronger goals for peer relationships (Patrick, Hicks, and Ryan, 1997), and report greater psychological distress when experiencing social stress (Moran and Eckenrode, 1991), than males.

One limitation of the current study, as with most of the research involving talented adolescents, lies in the relatively homogenous sample; all adolescents were European American and came from middle-income families. There is clearly a need for research on talented and promising adolescents from a wider range of backgrounds (Eccles and Alfeld-Liro, in press).

Additionally, it appears likely that there was some confounding of activity domain and gender within the current study. Although the sample included many females who participated in traditionally male sports activities, there was uneven gender distribution within some of the activity domains. Despite the large pool from which participants were drawn (873), there were some activities that were represented only by talented females, such as dance and gymnastics. Therefore, whereas there appeared to be particularly salient social issues for dancers, it was not possible to tease apart factors related differentially to the activity itself and to gender. The underrepresentation of males in dance and gymnastics in the current study suggests that it will be necessary in future studies to specially target and 
recruit such adolescents from places such as dance studios or special camps for talented students.

In summary, the results of the current study have indicated that peers generally play an important role in supporting talented adolescents' development of their talent activities. This study has contributed to the research on talented adolescents by including participants who were talented in the arts, and by considering differences across talent domains. It has also indicated a need for further research with respect to gender differences in the way that adolescents' peer relationships support or undermine commitment to developing their talent.

\section{ACKNOWLEDGMENTS}

We are grateful to the adolescents and their parents for their participation in this study. We also thank our colleagues for their assistance: Jennifer Abraham, Amy Arbreton, Lisa Colarossi, Carol Freedman-Doan, Rena Harold, Rachel Heiman, Dana Fuller Johnson, and Kwang Suk Yoon.

\section{REFERENCES}

Barber, B. L., and Eccles, J. S. (1997, April). "I don't want to play any more": When do talented adolescents drop out of competitive athletics? In Barber, B. L. (Chair), Pursuing competence, excellence, and flow. Symposium conducted at the Society for Research on Child Development biennial meeting, Washington, $\mathrm{DC}$.

Baumeister, R. F., and Leary, M. R. (1995). The need to belong: Desire for interpersonal attachments as a fundamental human motivation. Psych. Bull. 117: 497-529.

Berndt, T. J. (1982). The features and effects of friendship in early adolescence. Child Develop. 53: $1447-1460$.

Bloom, B. S. (ed.). (1985), Developing talent in young people. Ballantine, New York.

Buhrmester, D., and Furman, W. (1987). The development of companionship and intimacy. Child Develop. 58: 1101-1113.

Carnegie Council on Adolescent Development (1992). A matter of time: Risk and opportunity in the nonschool hours. Carnegie Corporation, New York.

Clark-Lempers, D. S., Lempers, J. D., and Ho, C. (1991). Early, middle, and late adolescents' perceptions of their relationships with significant others. J. Adolesc. Res. 6: 296-315.

Csikszentmihalyi, M., and Larson, R. (1984). Being adolescent. Basic Books, New York.

Csikszentmihalyi, M., Rathunde, K., and Whalen, S. (1993). Talented teenagers: The roots of success and failure. Cambridge University Press, Cambridge, United Kingdom.

Duncan, S. C. (1993). The role of cognitive appraisal and friendship provisions in adolescents' affect and motivation toward activity in physical education. Res. Q. Exercise and Sport 64: 314-323.

Duncan, T. E., Duncan, S. C., and McAuley, E. (1993). The role of domain and gender-specific provisions of social relations in adherence to a prescribed exercise regimen. J. Sport Exercise Psychol. 15: $220-321$.

Eccles, J. (1985). Why doesn't Jane run? Sex differences in educational and occupational patterns. In Horowitz, F. D., and O'Brien, M. (eds.), The gifted and talented: A developmental perspective. Washington, DC, APA Press, pp. 251-295.

Eccles, J. S., and Alfeld-Liro, C. (in press). Not you! Not here! Not now! Barriers to talent development from childhood through adolescence. Proceedings of the Esther Katz Rosen Symposium on the Psychological Development of Gifted Children. American Psychological Association, Washington, DC.

Eccles, J. S., and Barber, B. (1999). Student council, volunteering, basketball, or marching band? What kind of extracurricular involvement matters? J. Adolesc. Res. 14: 10-43. 
Eccles, J. S., Blumenfeld, P. C., Harold, R. D., and Wigfield, A. L. (1990). Ontogeny of self and task concepts and activity choice. (Grant No. 2 RO1 HD17553-06). National Institute of Child Health and Human Development, Bethesda, MD.

Eccles, J., and Harold, R. D. (1992). Gender differences in educational and occupational patterns among the gifted. In Colangelo, N., Assouline, S. G., and Ambroson, D. L. (eds.), Talent development: Proceedings, from the 1991 Henry B. and Jocelyn Wallace National Research Symposium on Talent Development. Trillium Press, Unionville, NY, pp. 3-29.

Feldman, D. H. (1986). Nature's gambit. Basic Books, New York.

Fredricks, J. A., Alfeld-Liro, C., Patrick, H., Ryan, A. M., Heiman, R., Hruda, L. Z., and Eccles, J. S. (1997, April). Tracing talent development across time: An exploration of adolescent commitment to athletics and the arts. In Barber, B. L. (Chair), Pursuing competence, excellence, and flow. Symposium conducted at the Society for Research on Child Development biennial meeting. Washington, $\mathrm{DC}$.

Furman, W., and Buhrmester, D. (1992). Age and sex differences in perceptions of networks of personal relationships. Child Develop. 63: 103-115.

Harter, S. (1990). Self and identity development. In Feldman, S. S., and Elliott, G. R. (eds.), At the threshold: The developing adolescent. Harvard University Press, Cambridge, MT, pp. 352-387.

Hartup, W. W. (1993). Adolescents and their friends. In Laursen, B. (ed.), Close friendships in adolesrence. Jossey-Bass Inc., San Francisco, CA, pp. 3-22.

Hesse-Biber, S., Kinder, I. S., Dupis, P. R., Dupis, A., and Tornabene, E. (1994). HyperResearch: A content analysis tool for the qualitative researcher. Researchware, Inc., Randolph, MA.

Horowitz, F. D., and O'Brien, M. (1986). Gifted and talented children: State of knowledge and directions for research. Am. Psychologist 41: 1147-1152.

Juvonen, J., and Wentzel, K. R. (eds.) (1996). Social motivation: Understanding children's school adjustment. Cambridge University Press, New York.

Karweit, N. (1983). Extracurricular activities and friendship selection. In Epstein, J. L., and Karweit N. (eds.), Friends in school: Patterns of selection and influence in serondary schools. Academic Press, New York, pp. 131-139.

Kunesh, M. A., Hasbrook, C. A., and Lewthwaite, R. (1992). Physical activity socialization: Peer interactions and affective responses among a sample of sixth grade girls. Soc. Sports J. 9: 385396.

Miles, M. B., and Huberman, A. M. (1994). Qualitative data analysis (2nd ed.). Sage, Thousand Oaks, CA.

Monsaas, J. A., and Engelhard, G. (1990). Home environment and the competitiveness of highly accomplished individuals in four talent fields. Develop. Psychol. 26: 264-268.

Moran, P. B., and Eckenrode, J. (1991). Gender differences in the costs and benefits of peer relationships during adolescence. J. Adolesc. Res. 6: 396-409.

O'Brien, S. F., and Bierman, K. L. (1988). Conceptions and perceived influence of peer groups: Interviews with preadolescents and adolescents. Child Develop. 59: 1360-1365.

Patrick, H., Hicks. L., and Ryan, A. M. (1997). Relations of perceived social efficacy and social goal pursuit to self-efficacy for academic work. J. Early Adolesc. 17: 109-128.

Rathunde, K., and Csikszentmihalyi, M. (1993). Undivided interest and the growth of talent: A longitudinal study of adolescents. J. Youth Adolesc. 22: 385-405.

Savin-Williams, R. C., and Berndt, T. J. (1990). Friendship and peer relations. In Feldman, S. S., and Elliott, G. R. (eds.), At the threshold: The developing adolescent. Harvard University Press, Cambridge, MA, pp. 277-307.

Scanlan, T. K., Carpenter, P. J., Lobel, M., and Simons, J. P. (1993). Sources of enjoyment for youth sport athletes. Ped. Exercise Sci. 5: 275-285.

Scanlan, T. K., Stein, G. L., and Ravizza, K. (1989). An in-depth study of former elite figure skaters: II. Sources of enjoyment. J. Sport Exerrise Psychol. 11: 65-83.

Weiss, M. R., and Petlichkoff, L. M. (1989). Children's motivation for participation in and withdrawal from sport: Identifying the missing links. Ped. Exer. Sci. 1: 195-211.

Weiss, M. R., Smith, A. L., and Theeboom, M. (1996). "That's what friends are for": Children's and teenagers' perceptions of peer relationships in the sport domain. J. Sport Exercise Psychol. 18: 347-379.

Whalen, S., and Csikszentmihalyi, M. (1989). A comparison of the self-image of talented teenagers with a normal adolescent population. J. Youth Adoless. 18: 131-146. 